\title{
Mediating Role of Job Burnout and Organizational Cynicism in the Relationship between Veteran's Psychological Capital and Well-being
}

\section{ART ICLE INF O}

\section{Article Type}

Descriptive Study

\section{Authors}

Gharibi M.* PhD,

Jamali Ghomi A. ${ }^{1} M S c$, Izadi B. ${ }^{2} M S c$

How to cite this article
Gharibi M, Jamali Ghomi A, Iz-adi
B. Mediating Role of Job Burnout
and Organizational Cynicism in
the Relationship between Veter-
an's Psychological Capital and We-
ll-being. Iranian Journal of War
\& Public Health. 2017;9(2):85-90.

*Public Administration Department, Management \& Accounting Faculty, Shahid Beheshti University, Tehran, Iran

${ }^{1}$ Public Administration Department, Management \& Accounting Faculty, Shahid Beheshti University, Tehran, Iran

${ }^{2}$ Public Administration Department, Management Faculty, Tehran University, Tehran, Iran

\section{Correspondence}

Address: Management \& Accounting Faculty, Shahid Beheshti University, Evin Square, Tabnak Street, Chamran Highway, Tehran, Iran. Postal Code: 1988396411

Phone: +98 (21) 85352345

Fax: +98 (21) 22431645

gharibi.mojtaba87@gmail.com

\section{Article History}

Received: October 30, 2016

Accepted: January 31, 2017

ePublished: April 24, 2017

\section{A B S T R A C T}

Aims Since many veterans are employees of the public organizations, their successful job performance improves the quality of services for the citizens. The aim of the study was to determine the mediating role of burnout and organizational cynicism in a correlation between psychological capital and psychological well-being in the veterans.

Instrument \& Methods In the descriptive correlational study, 384 veterans, who were employees of the state organizations in Tehran, were studied in 2016. The subjects were selected via available, non-probability sampling method. Data was collected by the psychological capital scale, the psychological well-being scale, the burnout scale, and the organizational cynicism scale. Data was analyzed by LISREL 8/8 software using descriptive statistics, Pearson correlation coefficient, and structural equation modeling via path analysis method.

Findings Psychological capital positively and significantly correlated with psychological well-being $(r=0.928)$, while it negatively and significantly correlated with burnout $(r=-0.932)$ and organizational cynicism ( $\mathrm{r}=-0.890)$. In addition, organizational cynicism ( $\mathrm{r}=-0.854)$ and burnout $(r=-0.915)$ negatively and significantly correlated with psychological well-being $(\mathrm{p}<0.01)$.

Conclusion Reducing burnout and organizational cynicism, psychological capital increases psychological well-being in the veterans.

Keywords Psychological Capital; Burnout; Organizational Cynicism; Mental Health; Veterans

\section{I T A T I O N L I N KS}

[1] 5-year study of change in the relationship between well-being ... [2] Very happy ... [3] Job satisfaction and psychological well-being as no additive ... [4] The effect of turnover on work satisfaction and mental health: Support for a situational ... [5] CThe absence of positive psychological (eudemonic) well-being as a risk factor for depression: A ten year ... [6] Influence of psychological contract breach on organizational ... [7] Impact of positive psychological capital on employee wellbeing over ... [8] The structure of psychological well-being ... [9] Commitment, psychological well-being and job performance ... [10] Workaholism, burnout, and work engagement: Three of a kind or three different kinds... [11] Job insecurity and psychological well-being: Review of the literature ... [12] Learning how to recover from job stress: effects of a recovery training program on recovery, recovery-related selfefficacy ... [13] Ten years on: A review of recent research on the Job Demand-Control (-Support) model and psychologica ... [14] The nonlinear effects of job complexity [15] Em-ployee commitment and well-being: A critical review, theoretical framework ... [16] Transformational leadership and employee well-being ... [17] Contagion effect of global leaders' positive psychological capital on followers: Does distance and quality of ... [18] Positive psychological capital: Measurement and relationship with performance and... [19] Relationship of core self-evaluations traits--self-esteem, generalized self-efficacy, locus of control, and emotional stability--with job satisfaction and job performance ... [20] Relationship of core self-evaluations to goal ... [21] The impact of cynicism on ethical intentions of Indian managers: The moderating ... [22] Organizational cynicism of the research assistants: A case of Akdeniz ... [23] Organizational change cynicism: The role of employee ... [24] Antecedents and consequences of employee organizational ... [25] Happiness is everything, or is it? explorations on ... [26] Job ... [27] Psychological syndrome of ... [28] Managing credit and mental characteristics ... [29] Organizational [30] Dimensions of teacher ... [31] The relationship between empowerment and ... 
جسمانى و طول عمر ذهنى، با توجه به سطح شادكامى و

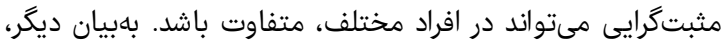

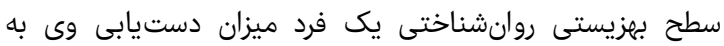

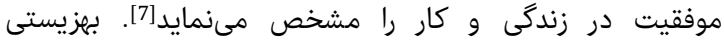

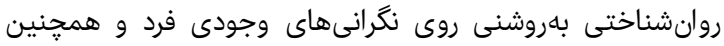

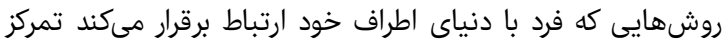

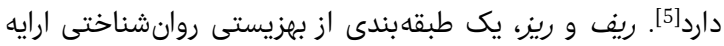

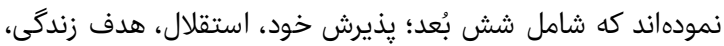

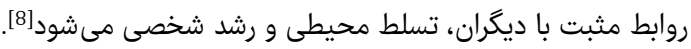

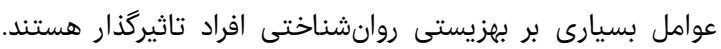

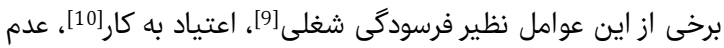

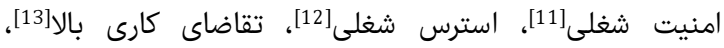

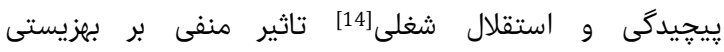
روانشناختى فرد داشته و برخى از عوامل نظير تعهد سازمانى [15ان،

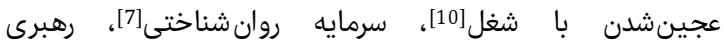

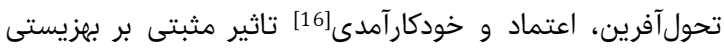

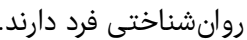

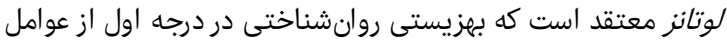

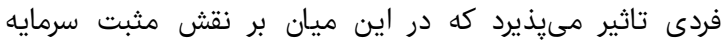

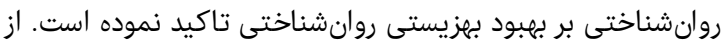

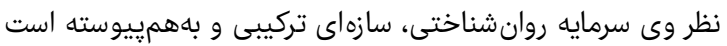

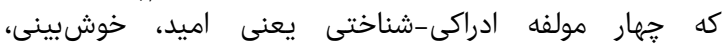

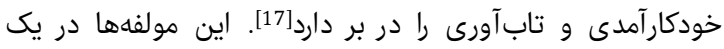

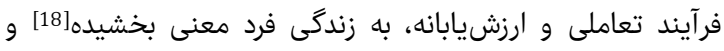

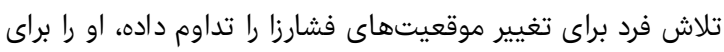

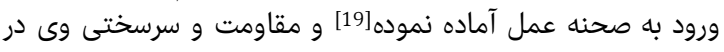

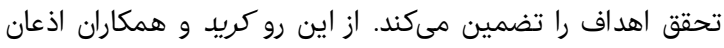

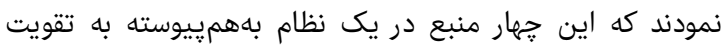

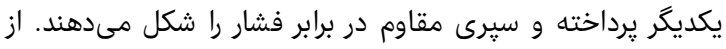

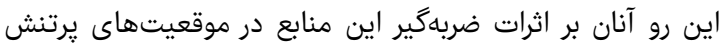

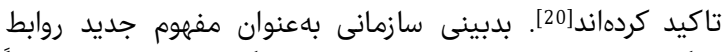

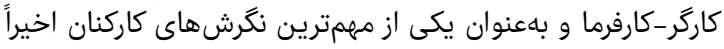

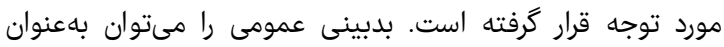

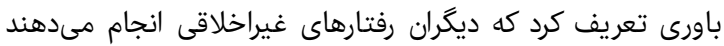

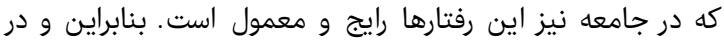

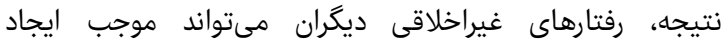

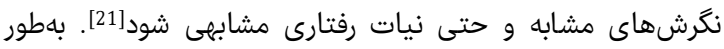

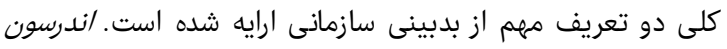

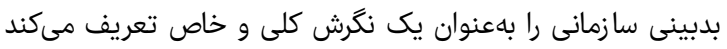

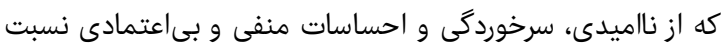

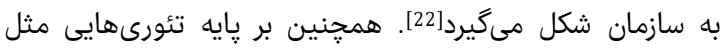

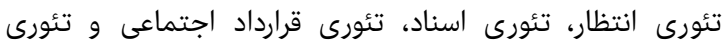

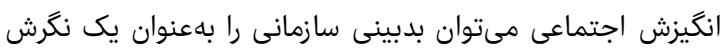

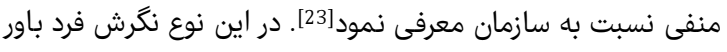

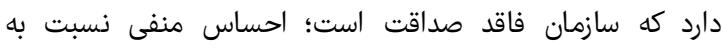

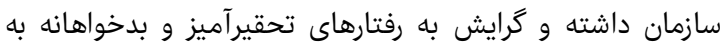

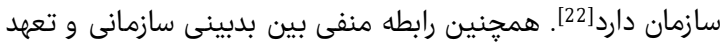

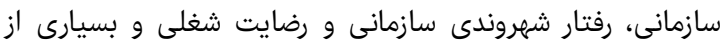
متغيرهاى ديكر وجود دارد [24].

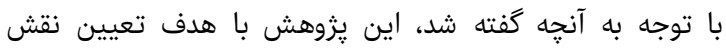

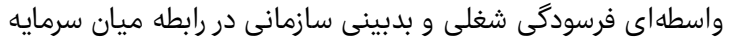

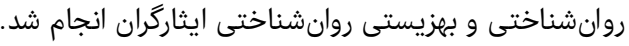

دوره 9، شماره r، بهار ع وسا
ميانجيكرى فرسودگى شغلى و بدبينى سازمانى در

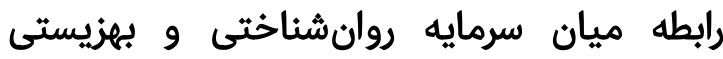
روان شناختى ايثارگران

مجتبى غريبى" PhD

گروه مديريت دولتى، دانشكده مديريت و مرابدارى، دانشگاه شهيد بهشتى،

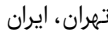

على جمالى قمى MSc

گروه مديريت دولتى، دانشكده مديريت و حسابدارى، دانشگاه شهيد بهشتى، تهران، ايران

MSc بهنوش ايزدى ايران

گُروه مديريت دولتى ، دانشكده مديريت ، دانشگًاه تهران، تهران، ايران

جكيده

اهداف: با توجه به اينكه بسيارى از ايثارگران در سازمانهاى عمومى كشور

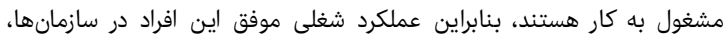

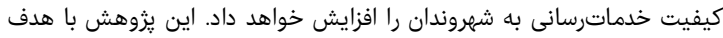

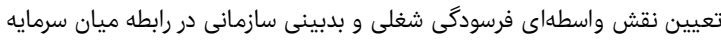

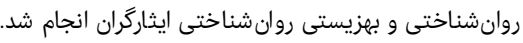

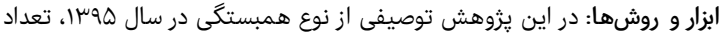

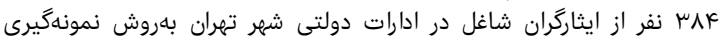

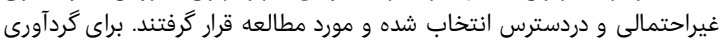

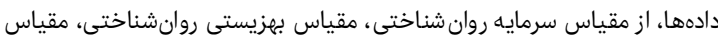

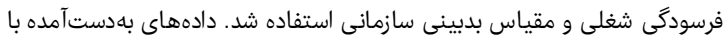
استفاده از نرمافزار

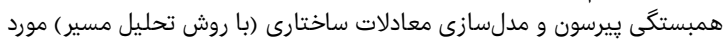

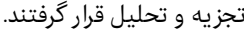

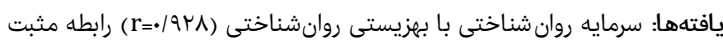

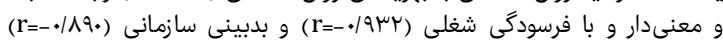

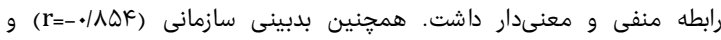

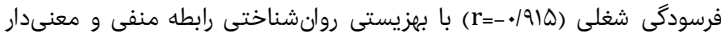

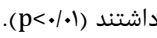

نتيجهكيرى: سرمايه روان شناختى از طريق كاهش فرسوداءنى شغلى و بدبينى

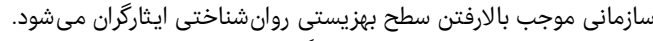

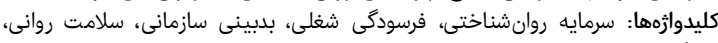

ايثاركران

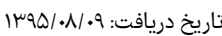
تاريخ קذيرش: تاريخ دريافت:

"نويسنده مسئول: gharibi.mojtaba87@gmail.com

مقدمه

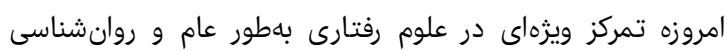

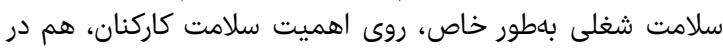

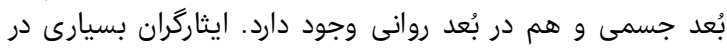

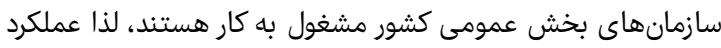

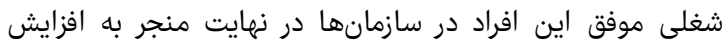

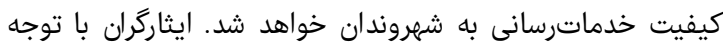

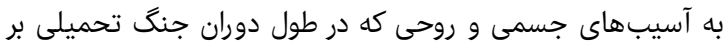

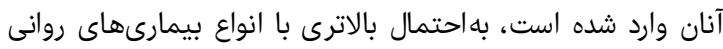

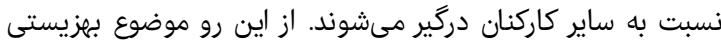
روانشناختى اين دسته از افراد در سازمانها از از اهميت دورجنا دورندانى

برخوردار است.

بهزيستى روانشناختى با كار و زندگى شخصى ارتى فرد ارتباط دارد.

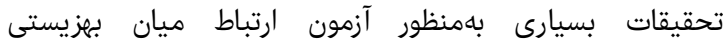

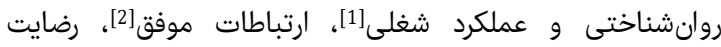

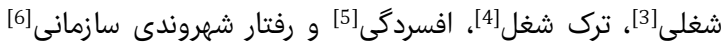

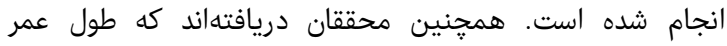

فصل نامه علمى - يُوهشى طب جانباز 


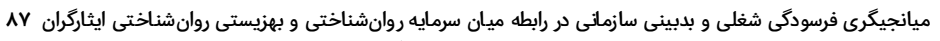

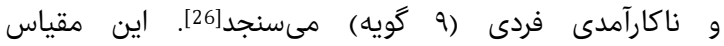

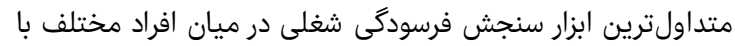

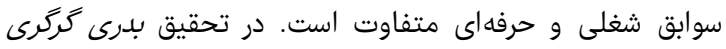

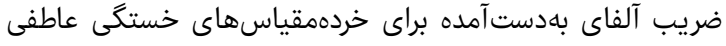

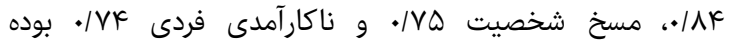

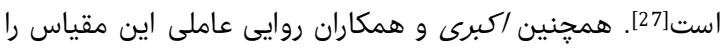

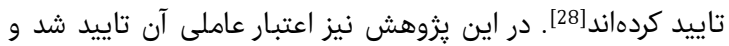

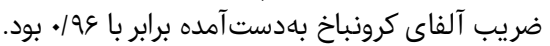

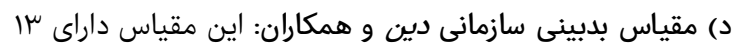

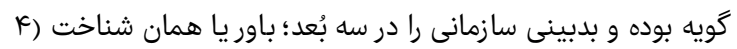

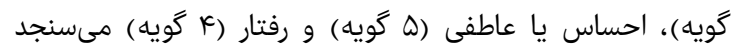

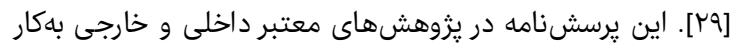

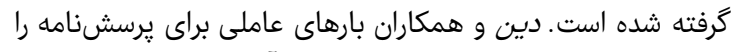

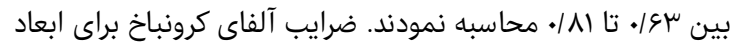

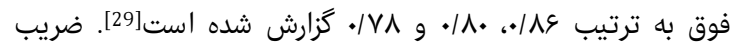

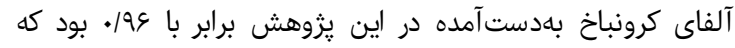

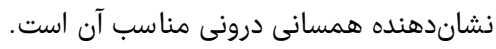
دادههاى بهدست آمده با استفاده از نرمافزار

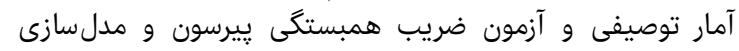

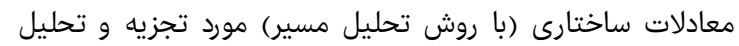

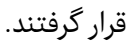

يافتهها بيشتر ياسخدهندكان، متاهل، داراى مدرك كارشناسى و سابقه كار

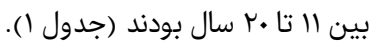

\begin{tabular}{|c|c|c|}
\hline درصد & تعداد & متغيرها \\
\hline & & وضعيت تاهل \\
\hline VI/S & rVQ & متاهل \\
\hline \multirow[t]{2}{*}{ rN/K } & 1.9 & مجرد \\
\hline & & سطح تحصيلات \\
\hline$\mu / / V$ & Irr & كاردانى و پاييينتر \\
\hline $\mathrm{kI} / \mathrm{V}$ & 19. & كارشناسى \\
\hline $18 / V$ & sk & كارشناسىارشد \\
\hline $9 / 9$ & $\mu_{\Lambda}$ & دكترى \\
\hline & & سابقه كار \\
\hline$F \Delta /$. & IV & تا •ا سال \\
\hline$k \& \mid V$ & 189 & التا •r سال \\
\hline$\Lambda / \mu$ & $\mu r$ & ا r سال و بالاتر \\
\hline
\end{tabular}

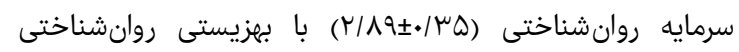

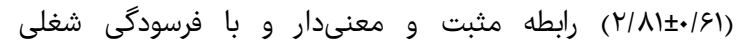

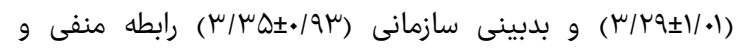

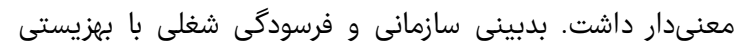

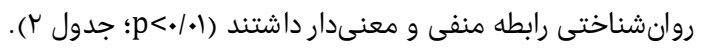

جدول r) ضرايب همبستخى يِيرسون بين متغيرهاى يزوهش (همه موارد در سطح 1. إ. معنى دار بودند)

\begin{tabular}{|c|c|c|c|}
\hline$\mu$ & r & 1 & متغيرها \\
\hline & & 1 & 1- سرمايه روانشناختى \\
\hline & 1 & -. & r- فرسودگى شغلى \\
\hline 1 & .1179 & $-\bullet / 19$. & "- - بديينى سازمانى \\
\hline.$- / 10 \varepsilon$ &.$- / 910$ & . $/ 94 \mathrm{~A}$ & ع- بهزيستى روانشناختى \\
\hline
\end{tabular}

اين يزوهش توصيفى از نوع همبستخى كه از لحاظ هدف، كاريردي

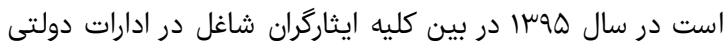

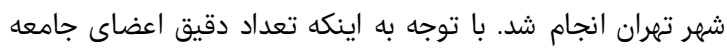

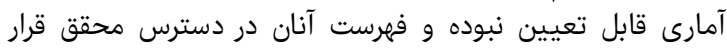

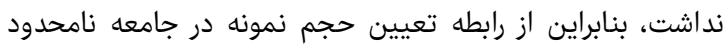

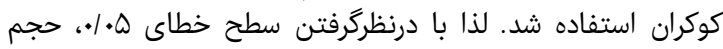

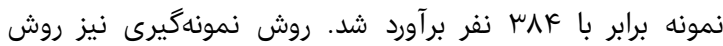

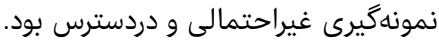

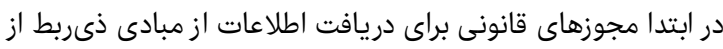

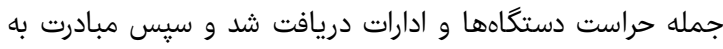

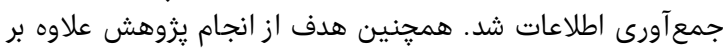

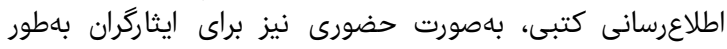

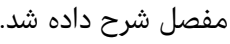

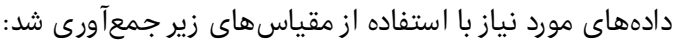

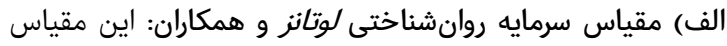

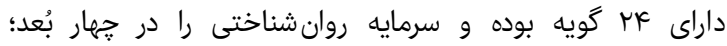

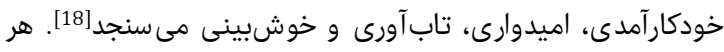

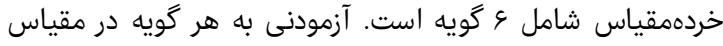

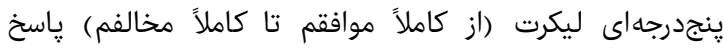

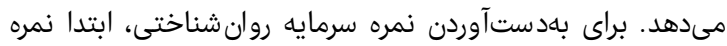

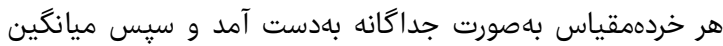

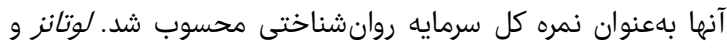

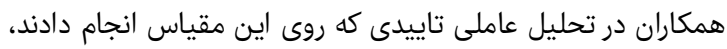

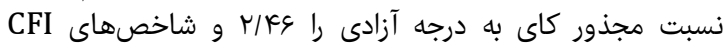
(شاخص برازش تطبيقى) و RMSEA (شاخص ريشه ميانكين

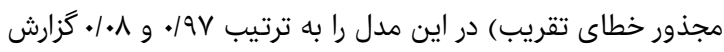

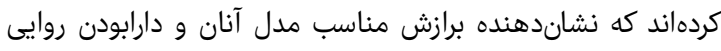

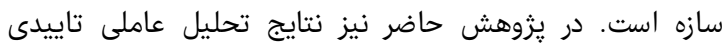

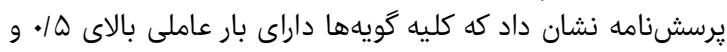

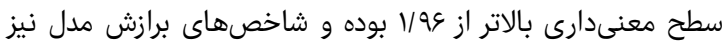

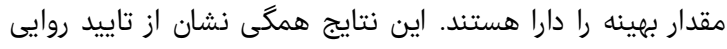

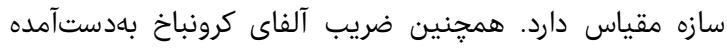

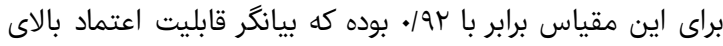
يرسشنامه است[18].

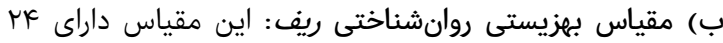

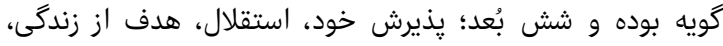

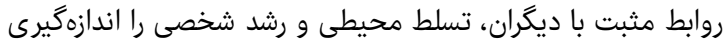

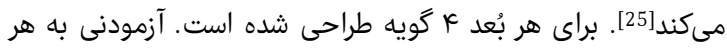

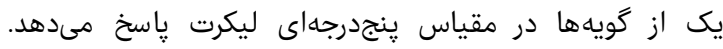

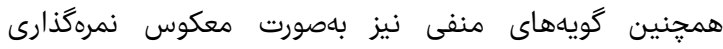

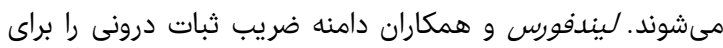

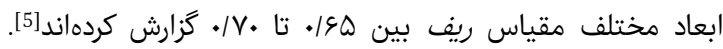
آلفاى كرونباخ بهدستآمده براى اين مقياس ريف در تحقيقى كه توسط

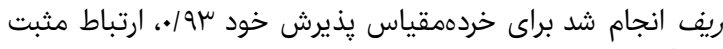

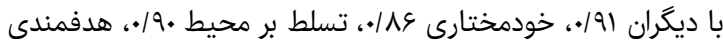

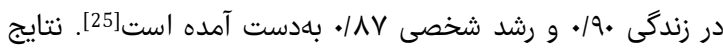

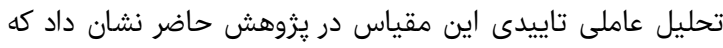

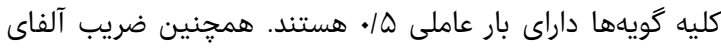

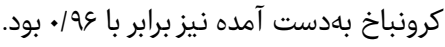

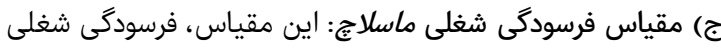

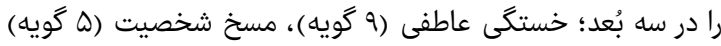




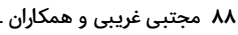

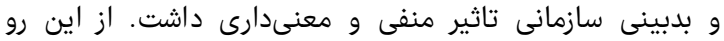

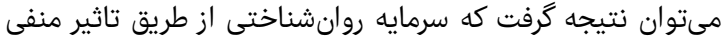

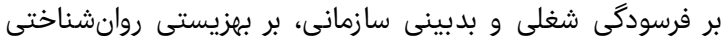

تاثير مثبتى دارد (شكل ()).
براساس نتايج تحليل مهكان مسير، ميزان اثر مستقيم سرمايه

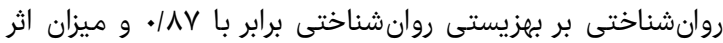

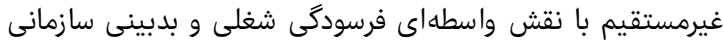

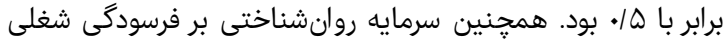

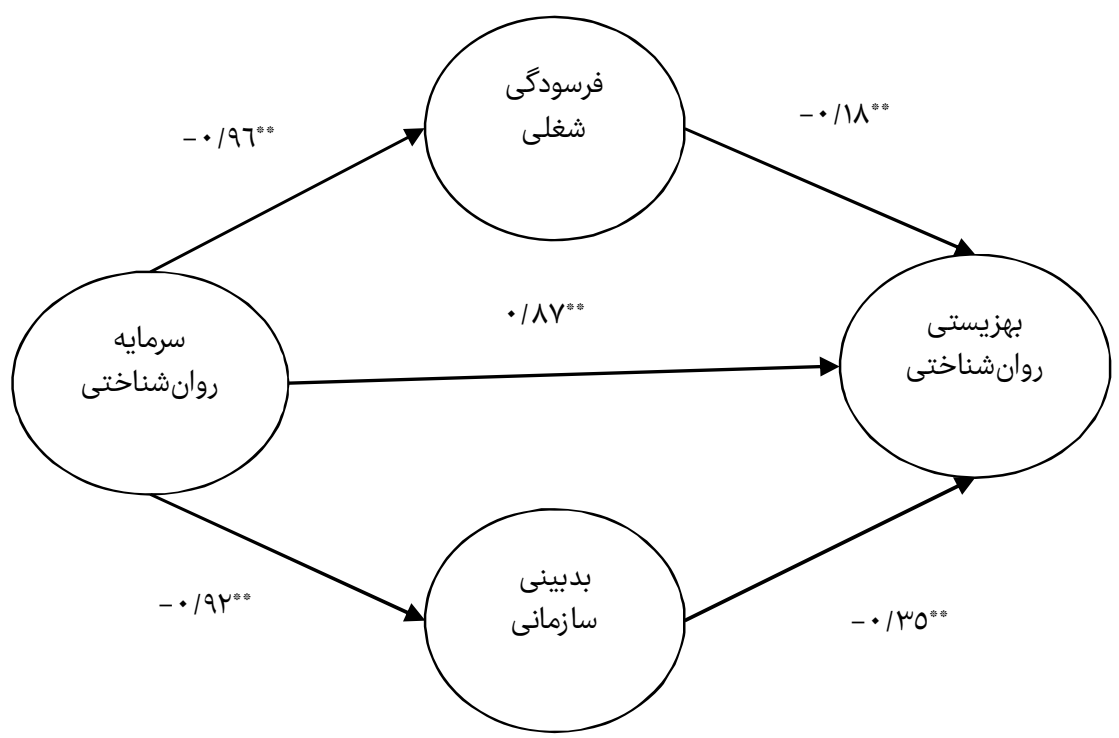

شكل ا) خروجى آزمون نقش واسطهاى فرسودگى شغلى و بدبينى سازمانى در رابطه ميان سرمايه روانشناختى و بهزيستى روانشناختى (همه موارد در سطح اء/• معنىار بودند)

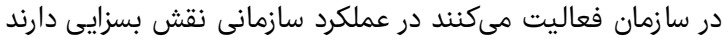

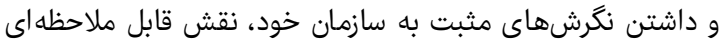

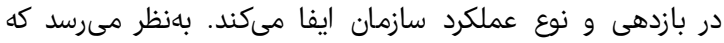

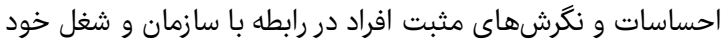

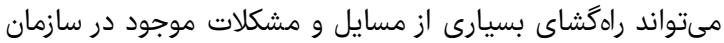

باشد.

يكى از عوامل مرتبط با شغل هر فرد، باورداشتن شاغل به توانايىها

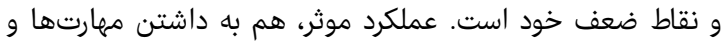

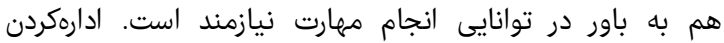

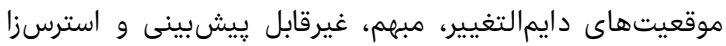

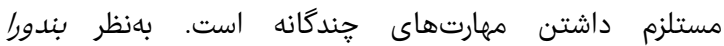

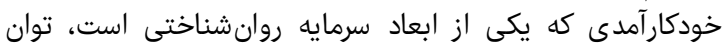

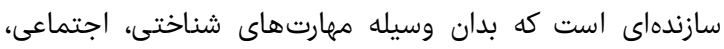

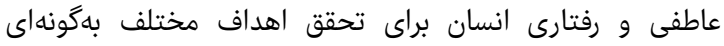

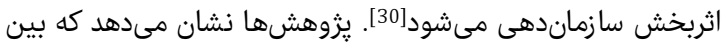

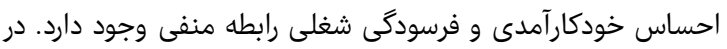

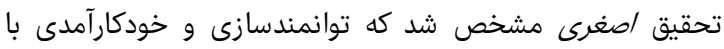

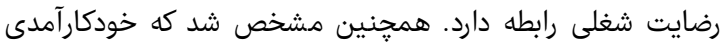

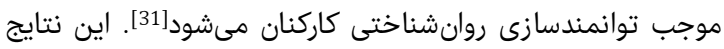

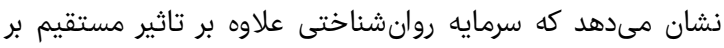

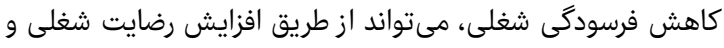

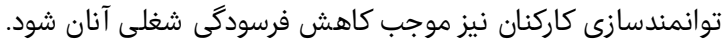

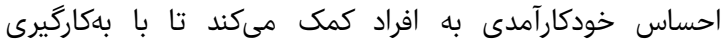

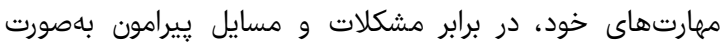

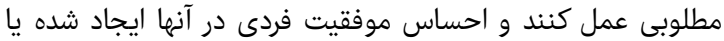

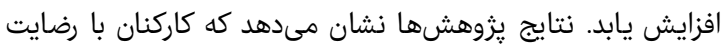

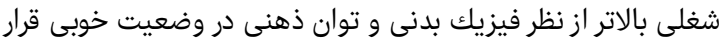
دوره 9، شماره r، بهار وجسا
يزوهش حاضر با هدف بررسى نقش واسطهاى بدبينى سازمانى و

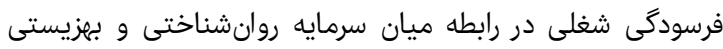

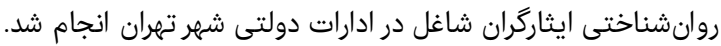

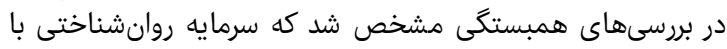

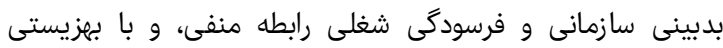

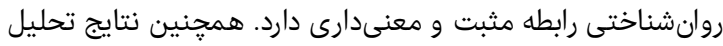

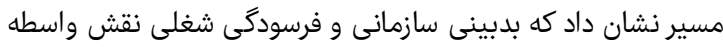

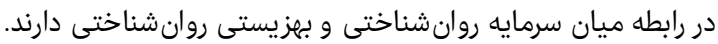

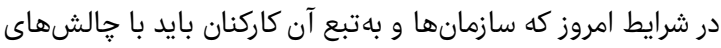

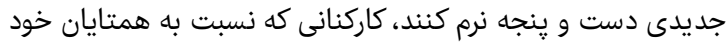

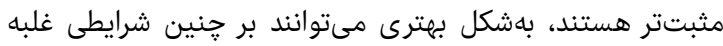

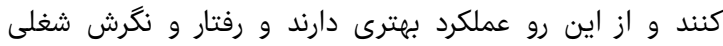

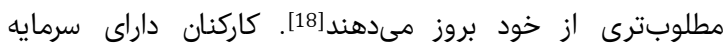

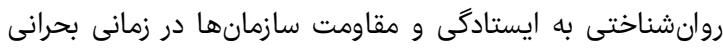

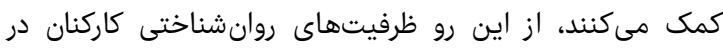

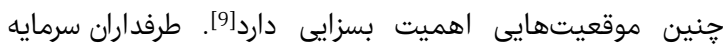

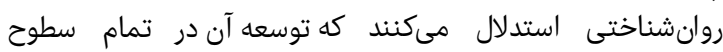

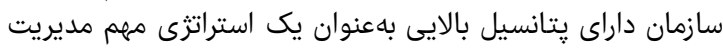

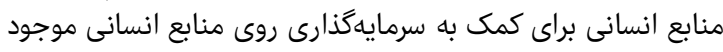

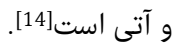

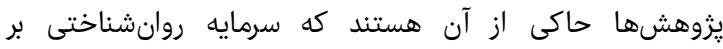

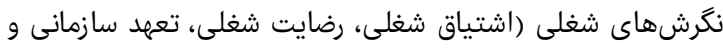

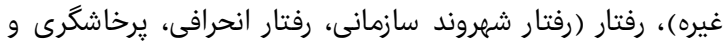

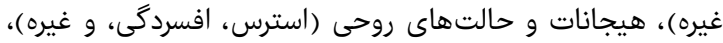

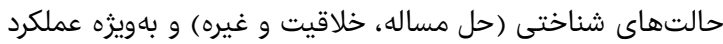
كارى فردى و سازمانى تاثير قابل ملاحظهاى دارئ دارد[19]. كاركنانى كه 
ميانجيكرى فرسودىى شغلى و بدبينى سازمانى رر رابطه ميان سرمايه روانشناختى و بجزيستى روان شناختى ايثارگران

depression: A ten year cohort study. J Affect Disord. 2010;122(3):213-7.

6- Jafri MH. Influence of psychological contract breach on organizational citizenship behavior and trust. Psychol Stud. 2012;57(1):29-36.

7- Avey JB, Luthans F, Smith RM, Palmer NF. Impact of positive psychological capital on employee well-being over time. J Occup Health Psychol. 2010;15(1):17-28.

8- Ryff, CD, Keyes CL. The structure of psychological well-being revisited. J Pers Soc Psychol. 1995;69(4):71927.

9- Wright TA, Hobfoll SE. Commitment, psychological well-being and job performance: An examination of conservation of resources (COR) theory and job burnout. J Bus Manag. 2004;9(4):389-406.

10- Schaufeli WB, Taris T W, Van Rhenen W. Workaholism, burnout, and work engagement: Three of a kind or three different kinds of employee wellbeing?. Appl Psychol. 2008;57(2):173-203.

11- Witte HD. Job insecurity and psychological wellbeing: Review of the literature and exploration of some unresolved issues. Eur J work Organ Psychol. 1999;8(2):155-77.

12- Hahn VC, Binnewies C, Sonnentag S, Mojza EJ. Learning how to recover from job stress: effects of a recovery training program on recovery, recovery-related self-efficacy, and well-being. J Occup Health Psychol. 2011;16(2):202-16.

13- Häusser JA, Mojzisch A, Niesel M, Schulz-Hardt S. Ten years on: A review of recent research on the Job Demand-Control (-Support) model and psychological well-being. J Work Stress. 2010;24(1):1-35.

14- Chung-Yan GA. The nonlinear effects of job complexity and autonomy on job satisfaction, turnover, and psychological well-being.J Occup Health Psychol. 2010;15(3):237-51

15- Meyer JP, Maltin ER. Employee commitment and well-being: A critical review, theoretical framework and research agenda. J Vocat Behav. 2010;77(2):323-37.

16- Liu J, Siu O L, Shi K. Transformational leadership and employee well-being: The mediating role of trust in the leader and self-efficacy. Appl Psychol. 2010;59(3):45479.

17- Story J, Youssef CM, Luthans F, Barbuto JE, Bovaird J. Contagion effect of global leaders' positive psychological capital on followers: Does distance and quality of relationship matter?. Int J Hum Resour Manag. 2013;24(13):2534-53

18- Luthans F, Avolio BJ, Avey JB, Norman SM. Positive psychological capital: Measurement and relationship with performance and satisfaction. Person Psychol. 2007;60(3):541-72.

19- Judge TA, Bono JE. Relationship of core selfevaluations traits--self-esteem, generalized self-efficacy, locus of control, and emotional stability--with job satisfaction and job performance: A meta-analysis. J Appl Psychol. 2001;86(1):80-92.

20- Erez A, Judge TA. Relationship of core selfevaluations to goal setting, motivation, and performance. J Appl Psychol. 2001;86(6):1270-9.

21- Nair P, Kamalanabhan TJ. The impact of cynicism on ethical intentions of Indian managers: The moderating role of seniority. J Int Bus Ethic. 2010;3(1):14.

22- Kalağan G, Aksu MB. Organizational cynicism of the research assistants: A case of Akdeniz University. Procedia Soc Behav Sci. 2010;2(2):4820-5.

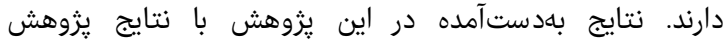

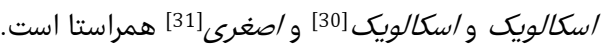

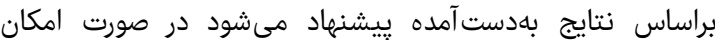

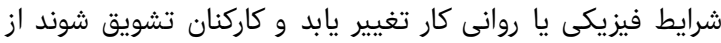
يذيرش مسئوليتهاى فراتر از توان خود خودئي از برنامههاى متنوع براى بهبود وضعيت جسمى كارئ كاركنان استفاده

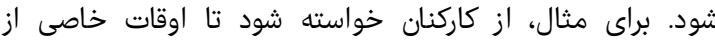

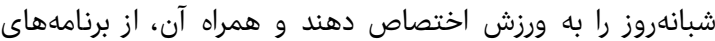

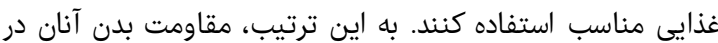

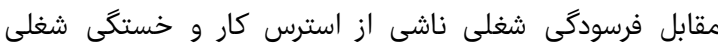

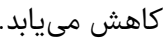

از محدوديتهاى تحقيق مئى مابوان به عدم كنترل ساير متغيرهاى

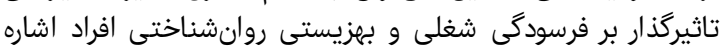

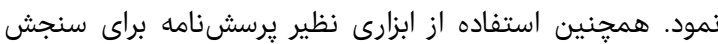

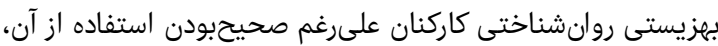

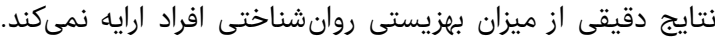

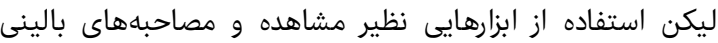

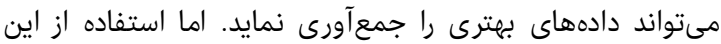

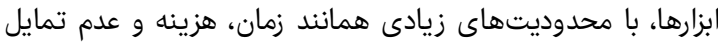
مشاركتكنندكان همراه است.

نتيجهكيرى سرمايه روانشناختى از طريق كاهش فرسودگى شغلى و بدبينى

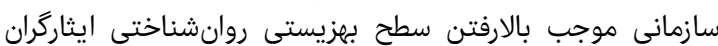

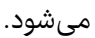

تشكر و قدردانى: از كليه ايثارگران محترمى كه در انجام اين

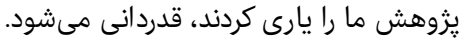

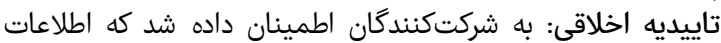

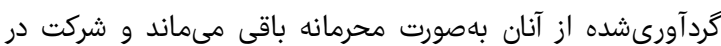

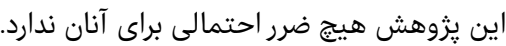

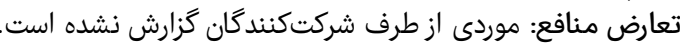

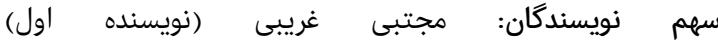

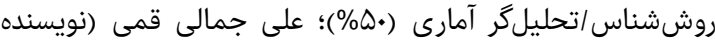

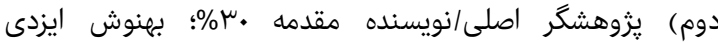

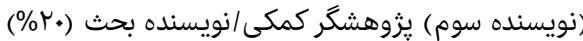

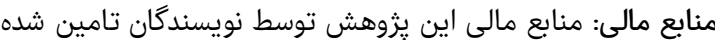
ست.

\section{منابع}

1- Cropanzano R, Wright TA. A 5-year study of change in the relationship between well-being and job performance. Consult Psychol J Pract Res. 1999;51(4):252-65.

2- Diener E, Seligman ME. Very happy people. Psychol Sci. 2002;13(1):81-4

3- Wright, TA, Bonett DG. Job satisfaction and psychological well-being as no additive predictors of workplace turnover. J Manag. 2007;33(2):141-60.

4- Wright TA, Bonett DG. The effect of turnover on work satisfaction and mental health: Support for a situational perspective. J Organ Behav. 1992;13(6):603-15.

5- Wood AM, Joseph S. The absence of positive psychological (eudemonic) well-being as a risk factor for 
Modares University; 1995. [Persian]

28- Akbari R, Ghaffar Samar R, Kiyani Gh, Eghtesadi AR. Managing credit and mental characteristics Maslach Burnout Inventory. Knowledge Health. 2011;6(3):1-8. [Persian]

29- Dean JW, Brandes P, Dharwadkar R. Organizational cynicism. Acad Manag Rev. 1998;23(2):341-52.

30- Skaalvik EM, Skaalvik S. Dimensions of teacher selfefficacy and relations with strain factors, perceived collective teacher efficacy, and teacher burnout. J Educ Psychol. 2007;99(3):611-25.

31- Asghari A. The relationship between empowerment and self-efficacy, job satisfaction. [Dissertation]. Tehran: Shahid Beheshti University; 2006. [Persian]

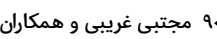

23- Brown M, Cregan C. Organizational change cynicism: The role of employee involvement. Hum Resour Manag. 2010;47(4):667-86.

24- Chiaburu DS, Peng AC, Oh IS, Banks GC, Lomeli, LC. Antecedents and consequences of employee organizational cynicism: A meta-analysis. J Vocat Behav. 2013;83(2):181-97.

25- Ryff CD. Happiness is everything, or is it? explorations on the meaning of psychological wellbeing. J Personal Soc Psychol. 1989;57(6):1069-81.

26- Maslach C, Schaufeli WB, Leite MP. Job burnout. Annu Rev Psychol. 2007;52(1):397-422.

27- Badri Gargari R. Psychological syndrome of burnout coping mechanisms [Dissertation]. Tehran: Tarbiat 